\title{
ANÁLISE DE ERROS NA GESTÃO DE PROCESSOS E NA ORGANIZAÇÃO DO TRABALHO EM HOSPITAIS
}

\section{ERRORS ANALYSIS ON MANAGEMENT PROCESSES AND WORK ORGANIZATION AT HOSPITALS}

\author{
Vivian Pizzato Nunes ${ }^{1}$, Fernando Gonçalves Amaral ${ }^{2}$ \\ ${ }^{1}$ Universidade Federal do Rio Grande do Sul - UFRGS - Porto Alegre - RS - Brasil \\ vivipn@gmail.com \\ ${ }^{2}$ Universidade Federal do Rio Grande do Sul - UFRGS - Porto Alegre - RS - Brasil \\ amaral@producao.ufrgs.br
}

\begin{abstract}
Resumo
O dinamismo e a complexidade dos processos da área da saúde e seus serviços afins implica em exigências de investimentos na área de processos e da organização do trabalho. Para se manter competitivo, como organização produtiva, o hospital também necessita se adequar às exigências do mercado atual, buscando o aperfeiçoamento dos seus procedimentos organizacionais. Este trabalho tem como objetivo a análise dos processos e da organização do trabalho no Centro de Materiais e Esterilização de um hospital, objetivando a otimização do setor, bem como a predição dos erros durante a execução das atividades observadas. Para a realização do estudo, foi utilizado o método Hierarchical Task Analisys (HTA), que permite apontar e prevenir erros e perdas por meio da hierarquização das tarefas e subtarefas do processo. Como resultado da pesquisa, obtevese o detalhamento dos procedimentos abordados, bem como a identificação de possíveis erros no processo e suas medidas preventivas.
\end{abstract}

Palavras-chave: processos; tarefas; HTA; melhorias de processos; hospitais.

\section{Introdução}

No cenário atual, a melhoria de processos é considerada ação básica para qualquer organização produtiva (pública, privada, terceiro setor) ter condições de responder às mudanças constantes na sua área de atuação e se manter competitiva. Coordenar o trabalho se faz necessário e seus mecanismos estão intrinsicamente relacionados à forma como os recursos e as atividades estão projetados, ao modo como essas atividades são geridas no dia-a-dia e aos meios pelos quais a organização gera o aprendizado, promove as melhorias nas operações e na forma de coordenar o trabalho. Assim, gerir processos é útil para qualquer tipo de organização, já que a necessidade de coordenar deriva exatamente da própria ação de dividir e organizar o trabalho (PAIM et al., 2009).

No ambiente hospitalar, a gestão de processos também é crucial para a manutenção da instituição no mercado. Para Bittar (1999), uma das atitudes básicas necessárias para se obter bons 
resultados nos serviços de saúde é a revisão ágil e constante dos processos, já que a rápida evolução tecnológica assim o exige, tendo como metas a inovação e a criatividade gerencial, tecnológica e estrutural. Segundo Merhy e Cecílio (2002), sobrevive o hospital que produz melhores produtos por meio de uma política agressiva de incorporação tecnológica e um crescente aperfeiçoamento e controle de seus processos internos. Quem não se atualiza, buscando reengenharias internas, e não moderniza seus processos de gestão, termina ultrapassado pela onda de modernização, competitividade e eficiência - marcantes em nossos tempos.

Estas constatações contrastam com os achados de Vlastarakos e Nikolopoulos (2007), em que a grande maioria dos profissionais de saúde acredita que a administração do hospital é ineficaz. A dificuldade na gestão de processos e organização do trabalho hospitalar ocorre tanto em atividades fim, quanto em tarefas organizacionais. Segundo GOMES (2009), o Centro Cirúrgico exige uma organização específica, em que há um tempo determinado para o desenvolvimento dos procedimentos da assistência cirúrgica, demandando o controle de todos os procedimentos e exigindo os recursos necessários para realizar o ato cirúrgico. Ainda, dentre outros fatores, as fragmentações de tarefas e as dificuldades de comunicação podem desencadear em uma organização do trabalho insatisfatória, sendo necessária a estruturação de uma organização para que o trabalho seja realizado no hospital como um todo (ROSA, 2010; SCHLOSSMACHER, 2012).

De outra forma, destaca-se também que a escassez de recursos é uma constante nas áreas da saúde. Conforme dados de 2009 do IBGE, os gastos públicos em saúde somam 3,6\% do Produto Interno Bruto (PIB) e os privados representam 4,9\%, enquanto em países desenvolvidos esse gasto é de $7 \%$ a $8 \%$ do PIB. Assim, faz-se necessária uma gestão criteriosa dos processos, buscando otimizar os recursos disponíveis para que seja atendido o maior número possível de pessoas com qualidade, o que demonstra a necessidade de pesquisas nessa área.

Considerando o exposto, este artigo objetiva analisar os processos e a organização do trabalho do Centro de Materiais e Esterilização de um hospital, a fim de identificar e prevenir erros e perdas em processos, sugerindo modificações que resultem em melhorias para a organização. A análise utilizada é estruturada através do método HTA (Hierarchical Task Analysis), destinado a decompor as tarefas em uma hierarquia de tarefas e subtarefas, a fim de identificar quais tendem a falhar ou provocar problemas de execução e propor soluções para o processo (STANTON, 2005).

Este artigo está organizado conforme segue. Após a introdução, a seção 2 apresenta a Revisão da Literatura sobre o tema. A seção 3 compreende os Procedimentos Metodológicos de realização da pesquisa. A seção 4 aborda os resultados do trabalho de campo, além da sua discussão. Finalmente, a seção 5 versa sobre as conclusões do estudo, bem como suas limitações e oportunidades de trabalhos futuros. 


\section{Referencial Teórico}

\subsection{Gestão de Processos em ambiente hospitalar}

Nas últimas décadas, a gestão hospitalar no Brasil tem se destacado. O motivo, fundamentalmente, deriva do conceito de hospital, que evoluiu no sentido de não mais se entender e pensar o hospital como um ambiente social e religioso, mas sim como um espaço de produção, ancorado em processos econômicos e tecnológicos, como de uma empresa (RUBIO e CONESA apud PONTALTI, 2002).

O hospital é uma organização complexa, onde atividades industriais são mescladas com ciência e tecnologia de procedimentos utilizados diretamente em humanos, com componentes sociais, culturais e educacionais, interferindo na estrutura, no processo e nos resultados (BITTAR, 1997). Assim, espera-se que o serviço de saúde seja realizado com qualidade pela instituição, de acordo com as necessidades da sociedade. Para Duarte (1995), trata-se de um dos mais complexos tipos de organização que o mundo moderno conhece, não só pela sofisticada tecnologia necessária ao seu funcionamento, mas também pela peculiar prestação do serviço, pois atende pessoas que necessitam obter como produto final a cura de seu corpo.

O rápido desenvolvimento da tecnologia médica, a grande expansão dos conhecimentos, a ampliação progressiva do campo de atuação dos agentes de saúde, a acentuada diversificação das especialidades médicas tornam o hospital uma instituição dinâmica (DUARTE, 1995). De acordo com Rosa (1989), o serviço hospitalar caracteriza-se pelo trabalho intensivo no qual se exige dos funcionários alta produtividade em tempo limitado.

Bratz (2001), no que diz respeito à preocupação com a competitividade no setor hospitalar, indicava que o principal fator era a velocidade e agilidade dos serviços. Se considerados fatores como a grande complexidade, o elevado custo e a alta qualidade que as pessoas buscam na saúde, o número de pessoas que precisam de atendimento, conclui-se que existe uma crise na área da saúde. Porém, paradoxalmente, considerando o desenvolvimento tecnológico e de recursos humanos, pode-se oferecer um melhor atendimento em saúde. Portanto, a crise não se deve à qualidade dos médicos, das enfermeiras e da tecnologia, que hoje está num patamar elevado. A crise então está no gerenciamento da saúde, que é carente, entre outras coisas, de ferramentas específicas para o aumento da produtividade (BITTAR, 1999). Assim, os processos, através dos programas e serviços, necessitam ser avaliados e controlados quanto a sua efetividade, eficácia, eficiência, produção, produtividade e qualidade.

Para Paim et al. (2009) quanto maior a complexidade da coordenação do trabalho através do sistema produtivo, maior a necessidade de se desenvolver a capacidade de gerir processos. Essa 
capacidade tem sido vista como uma forma eficaz de promover integração, dinâmica, flexibilidade e inovação nas organizações, de certa forma proporcionando paridade e/ou vantagem competitiva.

Pode-se definir processo como uma combinação dos elementos, equipamentos, insumos, métodos ou procedimentos em condições ambientais, pessoas, informações do processo ou medidas, tendo como objetivo a fabricação de um bem ou o fornecimento de seu serviço (WERKEMA, 1995). Já Harrington (1991), define processo como qualquer atividade que recebe uma entrada (input), agrega-lhe valor e gera uma saída (output), para um cliente interno ou externo.

O Gerenciamento de Processos pode ser definido como uma metodologia aplicada tanto em empresas que produzem bens manufaturados, quanto na produção de serviços, visando implementar a melhoria contínua (PASQUALI, 2002). Para Gadd (1995), o Gerenciamento de Processos relaciona-se, dentre outros, com a maneira pela qual a organização gerencia de forma sistemática seus processos e como implementa mudanças nestes, avaliando os seus benefícios.

Segundo Harrington (1991), cada processo, cada atividade, cada trabalho dentro de uma organização existe por uma única razão: para oferecer aos clientes e/ou consumidores produtos e serviços que lhes representam valor. A melhora de qualquer atividade tem um impacto positivo no cliente externo. Assim, dedicar mais esforço para melhorar processos de negócio é um fator importante para a empresa ser competitiva. O foco no aperfeiçoamento dos seus processos resulta em diversos benefícios para organização, tais como: permite prever e controlar alterações; reforça a capacidade de competir, melhorando a utilização dos recursos disponíveis; fornece um meio para efetuar grandes mudanças em atividades muito complexas de forma rápida; ajuda a gerir com eficácia as suas inter-relações; fornece uma visão sistemática das suas atividades; mantém o foco no processo; previne a ocorrência de erros; fornece uma visão de como os erros ocorrem e um método para corrigi-los.

Uma das maiores dificuldades encontradas para o entendimento dos processos como principal fator de desempenho da organização é a visualização da organização como grupos funcionais verticais que executam tarefas específicas, enquanto que o fluxo dos processos organizacionais é horizontal e compreende diversos grupos funcionais verticais simultaneamente (HARRINGTON, 1991). O fluxo de trabalho horizontal, combinado com uma organização vertical, resulta em muitas lacunas e superposições, gerando uma influência negativa na eficiência e na eficácia do processo. Quando não há atenção para o processo na sua totalidade, o resultado consiste em pequenas empresas isoladas, sendo avaliadas por padrões que não representam as necessidades da empresa como um todo levando a uma diminuição na otimização. 


\subsection{Gestão de Processos e Organização do Trabalho}

As organizações de saúde configuram-se em instituições complexas, em que convivem projetos políticos bastante diferenciados entre si, influenciando a gestão e organização do trabalho. A instituição hospitalar coloca-se como um amplo campo de disputas de grupos profissionais altamente qualificados e com grande autonomia de trabalho, os quais não se subordinam às chefias superiores ou a uma direção, no clássico modelo taylorista-fordista. Além disso, existe uma forte fragmentação das linhas de mando entre as várias categorias, e as corporações organizam-se, até certo ponto, segundo lógicas próprias (CECÍLIO apud MATOS e PIRES, 2006).

De outra forma, para Dejours et al. (1993) a organização do trabalho é a divisão das tarefas, que conduz alguns indivíduos, a definir por outros, o trabalho a ser executado, o modo operatório e os ritmos a seguir. Por outro lado, é a divisão dos homens, isto é, o dispositivo de hierarquia, de supervisão, de comando, que define e codifica todas as relações de trabalho.

A estrutura organizacional dos hospitais segue ainda atualmente as diretrizes estabelecidas por organogramas clássicos, as estruturas hierarquizadas verticais, fragmentação das responsabilidades, formalização das relações, pautando-se nas lógicas de autoridade legal, herdados da concepção burocrática (MATOS e PIRES, 2006). Neste contexto, uma das principais motivações para a gestão de processos tem sido a capacidade de contribuir para superar as limitações do modelo funcional de organização do trabalho. O modelo de gestão fundamentado na divisão do trabalho funcional, centrada na especialização, tem limitações com relação à capacidade de coordenação do trabalho. Esse modelo revela-se restritivo para lidar com a realidade contemporânea, na qual a construção de organizações mais ágeis, integradas e flexíveis passa a ser uma condição importante para a atuação que sustente e aprimore o desempenho organizacional. Além disso, os mecanismos de coordenação baseados em processos, dentro desse contexto, têm ampliado muito sua importância e repercussão (PAIM et al., 2009).

\subsection{Erros e fatores humanos na organização do trabalho hospitalar}

O ambiente hospitalar integra complexas interações entre os profissionais de saúde, pacientes e suas famílias e acompanhantes. Essa complexidade exige que a concepção do sistema seja ergonomicamente adequada com relação à organização do trabalho e ambiente, no que diz respeito à segurança dos profissionais de saúde, pacientes e seus acompanhantes (SERRANHEIRA et al., 2010). Segundo Carvalho e Cassiani (2000), os fatores relacionados à organização do trabalho (acúmulo de atividades, recursos humanos insuficientes e mal qualificados, falta de materiais, aparelhos e recursos financeiros) e ao ambiente (layout inadequado, interrupções durante 
a realização da atividade, ruídos, luminosidade inadequada) são decisivos para a ocorrência de erros na medicação de pacientes, por exemplo.

Para Carvalho e Vieira (2002), ao se analisar a origem dos erros e o porquê eles acontecem, é interessante comparar o setor de produção de uma indústria e a equipe de profissionais de um hospital. A indústria trabalha com a hipótese de que o erro humano é possível de acontecer e, baseado nessa premissa, desenvolve mecanismos capazes de preveni-los ou detectá-los precocemente no processo. Esses mecanismos têm por objetivo oferecer um produto final ao consumidor isento de falhas. Já no hospital, verifica-se a ausência de mecanismos que diminuam a ocorrência de erros, ou que o interceptem antes de chegar ao consumidor final (o paciente). Ou seja, trabalha-se com a premissa de que o profissional de saúde não comete erros e, portanto, não se criam mecanismos de prevenção e correção durante o processo.

Para Bates (2000), o setor hospitalar é como uma pequena indústria, com poucas ações padronizadas através de rotinas e relativamente pouca segurança em comparação com as áreas de manufatura. Assim, há a necessidade de mudar a abordagem atual do erro, focada no indivíduo, por outra visão mais sistêmica do problema. Na visão sistêmica, o erro é consequência de uma série de fatores, e tenta-se construir mecanismos de defesa, tais como na indústria, para evitá-lo ou diminuir seu impacto (REASON, 2000). Por isso, a prevenção de erros deve basear-se na busca de causas reais, que geralmente incluem erros de organização do trabalho e implementação do serviço no sistema como um todo (BERLIN et al. apud CARVALHO e VIEIRA, 2002).

\subsection{Análise de erros e fatores humanos na organização do trabalho hospitalar}

A ocorrência de erros, muitas vezes fatais, é uma realidade nas organizações hospitalares do Brasil e de outros países do mundo. Por exemplo, segundo James (2013), a cada ano nos Estados Unidos, entre 210 e 440 mil pacientes que são hospitalizados sofrem algum tipo de dano evitável que contribui para a sua morte.

Ao concordar em iniciar um tratamento médico, o paciente deve ter a garantia de que ele irá transcorrer com segurança para que obtenha o mais próximo possível do resultado desejado. $\mathrm{Na}$ área da saúde, a construção de um sistema seguro significa conceber os processos assistenciais de modo a salvaguardar os pacientes de injúrias acidentais (INSTITUTE OF MEDICINE, 2000). Dessa forma, um dos métodos mais aplicados na prevenção de erros na organização do trabalho hospitalar é o Hierarchical Task Analysis (HTA) ou Análise Hierárquica da Tarefa.

Segundo Reason (2002), uma análise de tarefas é fundamental, pois fornece as informações necessárias para a análise e previsão de erros do operador (metas, tarefas e subtarefas). Ainda, autores afirmam que o formato mais comum de apresentação de uma análise de tarefas é a hierárquica (HTA), a qual permite observar como as pessoas interagem com o equipamento e com 
aspectos do ambiente de trabalho e auxilia na predição do erro humano. O processo de construção de um HTA é esclarecedor por si só, ou seja, o entendimento da tarefa sob análise aumenta significativamente, e sua grande popularidade deve-se majoritariamente à flexibilidade e utilidade do seu resultado (KIRWAN; AINSWORTH, 1992; STANTON, 2005; SALMON et al., 2010).

Essa flexibilidade permitiu a aplicação do HTA a uma ampla gama projetos de sistema e avaliações, incluindo a previsão de erro humano e sua análise, (HODGKINSON; CRAWSHAW, 1985; LANE et al., 2007; ADAMS, DAVID, 2007; MILLS, 2007). No âmbito hospitalar, o HTA foi utilizado na predição de erros em processos utilizando equipamentos médicos, na predição de erros na administração de medicamentos e na análise de procedimentos cirúrgicos (CHUNG et al., 2003; LANE et al., 2006; SARKER et al., 2006; SARKER et al., 2008).

\section{Procedimentos Metodológicos}

Este estudo pode ser considerado de caráter aplicado, qualitativo e exploratório, caracterizado por uma abordagem de estudo de caso com características de pesquisa participante (YIN, 2001). A pesquisa foi realizada em uma unidade foco de um hospital.

O estudo dividiu-se em cinco etapas, conforme a Figura 1. A etapa 1, denominada Análise da Demanda, consistiu na visitação ao hospital e na verificação da viabilidade do estudo e das condições de trabalho. Na etapa 2 (Coleta de Dados) foram levantados indicadores e informações gerais referentes à organização. A etapa 3 constituiu o Diagnóstico da Situação Atual e caracterizou-se pela análise dos dados e informações coletados e escolha do processo foco. Na etapa 4, chamada de Análise Aprofundada, foi realizada uma entrevista com responsáveis pelo processo, construiu-se um HTA, confrontou-se esse resultado com o Procedimento Operacional Padrão (POP) do processo e foram identificados os problemas e prováveis erros. A quinta e última etapa chama-se Proposição de Melhorias e foi composta pela elaboração de soluções para os problemas, identificados na etapa anterior.

A Análise da Demanda foi realizada através de uma visita ao hospital e uma entrevista não estruturada com o responsável pela instituição, em que se verificou a possibilidade e as limitações da realização do estudo no local. Durante a entrevista foram levantadas informações gerais sobre o hospital, como estrutura organizacional e principais dificuldades enfrentadas pela instituição.

$\mathrm{Na}$ segunda parte do estudo, foram levantados os procedimentos padrão, indicadores de desempenho, processos críticos, regulamentos e boas práticas da instituição. A terceira parte foi realizada partir da análise dos dados, chegando a um Diagnóstico da Situação Atual, que permitiu escolher o processo foco a ser estudado.

Na sequência do Diagnóstico, realizou-se a Análise Aprofundada do processo escolhido, através de uma entrevista não estruturada com a supervisora e o responsável pela execução das 
tarefas do processo foco. Após, utilizou-se o método HTA para hierarquizar todas as operações que constituem o processo em tarefas e subtarefas e comparou-se com o respectivo Procedimento Operacional Padrão (POP) e com o realizado na prática. Os passos seguidos para realizar o HTA foram: i) definir processo a ser analisado; ii) coletar dados específicos relacionados à tarefa; iii) determinar o objetivo geral do processo; iv) detalhar objetivo em metas; v) decompor em tarefas e subtarefas; vi) realizar um plano de análise (STANTON apud KLOECKNER et al., 2013). Em seguida, identificaram-se os problemas e prováveis erros nas operações em conjunto com a supervisora.

Figura 1- Procedimentos Metodológicos

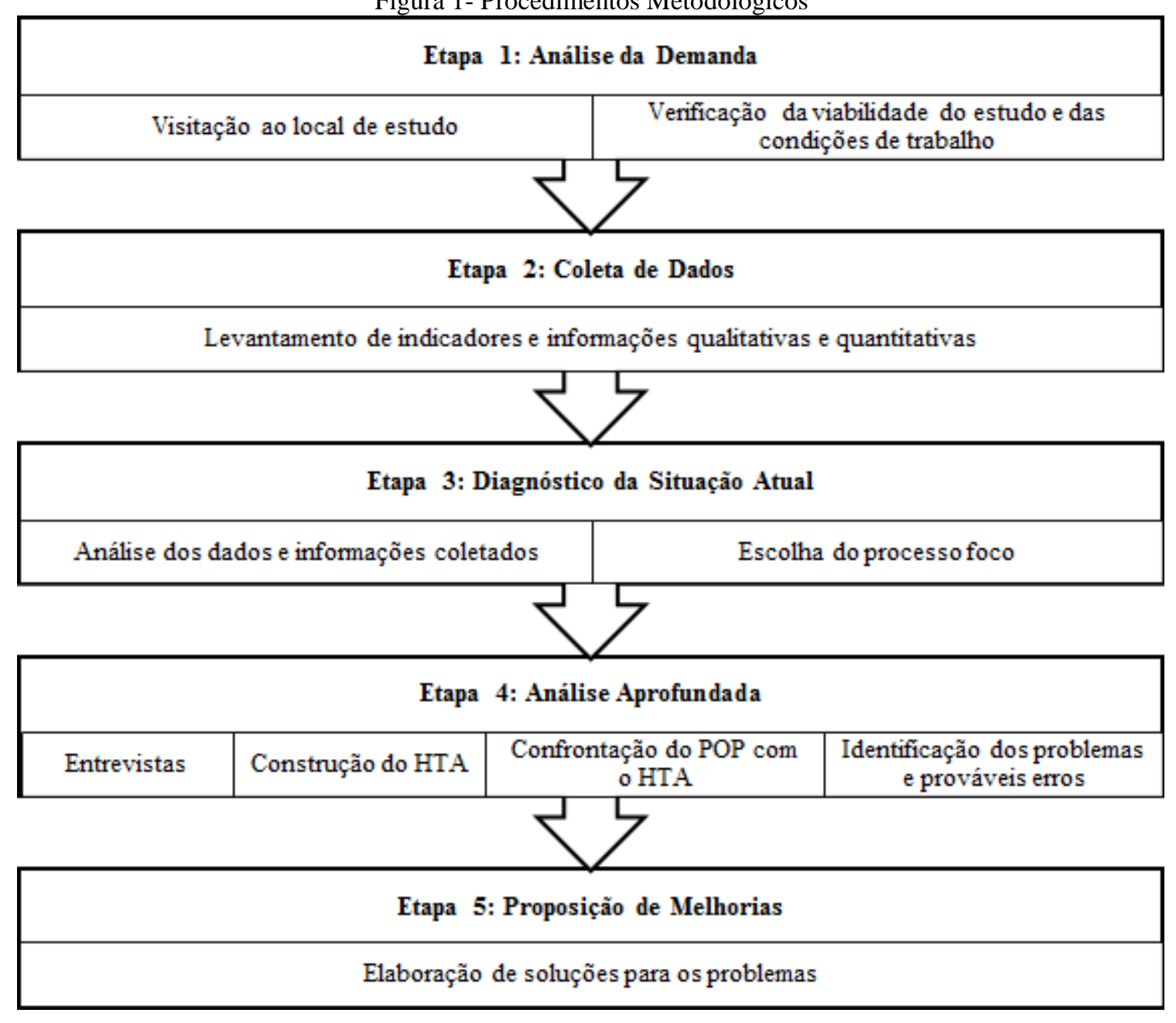

Por último, a etapa de Proposição de Melhorias foi marcada pela elaboração de soluções para os problemas encontrados na análise anterior, em conjunto com a supervisora. Foi construída uma tabela que organiza os prováveis erros em cada tarefa/subtarefa e sugere uma medida preventiva e/ou reativa para esses erros.

\section{Resultados}


Este trabalho foi realizado em um hospital que possui cerca de 480 funcionários e realiza diversos tipos de atendimentos, tais como: ambulatorial, pediátrico, oftalmológico, traumatólogico, além de procedimentos cirúrgicos. O setor escolhido de acordo com a metodologia, para realizar o estudo de caso, foi o Centro de Material e Esterilização (CME). Essa decisão foi motivada, principalmente, pela importância do setor para o hospital em contraponto com a escassez de recursos humanos disponíveis para a realização dos seus procedimentos dentro da organização. Segundo a ANVISA (2012), o CME é responsável pela recepção, limpeza, preparo, desinfecção ou esterilização, armazenamento e distribuição de produtos para saúde, e se caracteriza, muitas vezes, pelo processamento de produtos críticos para a saúde, que devem ser submetidos ao processo de esterilização, a fim de eliminar a vida microbiológica e prevenir contaminações.

Dentro do CME, optou-se por analisar o processo de limpeza e secagem, que antecede a esterilização. Para garantir a sua efetividade, a esterilização deve ser precedida por um processo de limpeza e secagem rigorosos, pois a sujeira e a gordura atuam como fatores de proteção para os micro-organismos, impedindo o contato dos agentes desinfetantes e esterilizantes (SOBECC, 2000). A ANVISA (2012) define limpeza como a remoção de sujidades orgânicas e inorgânicas, redução da carga microbiana presente nos produtos para saúde, utilizando água, detergentes, produtos e acessórios de limpeza, por meio de ação mecânica (manual ou automatizada), atuando em superfícies internas (lúmen) e externas, de forma a tornar o produto seguro para manuseio e preparado para desinfecção ou esterilização.

\subsection{Análise do processo}

O processo a ser estudado compreende as etapas de recepção, limpeza, secagem e preparação dos materiais, que são anteriores à esterilização (Figura 2). Para realizar o estudo, foram realizadas duas entrevistas não estruturadas. A primeira entrevistada foi a supervisora do setor, na qual explicou passo a passo o POP $n^{\circ} 23 / 03$ (Figura 3), que discorre principalmente sobre a limpeza e secagem do instrumental e brevemente sobre a preparação. Não há POP para a recepção dos materiais. Após, o responsável pela execução das tarefas foi entrevistado e observado durante a realização dos procedimentos em análise. 


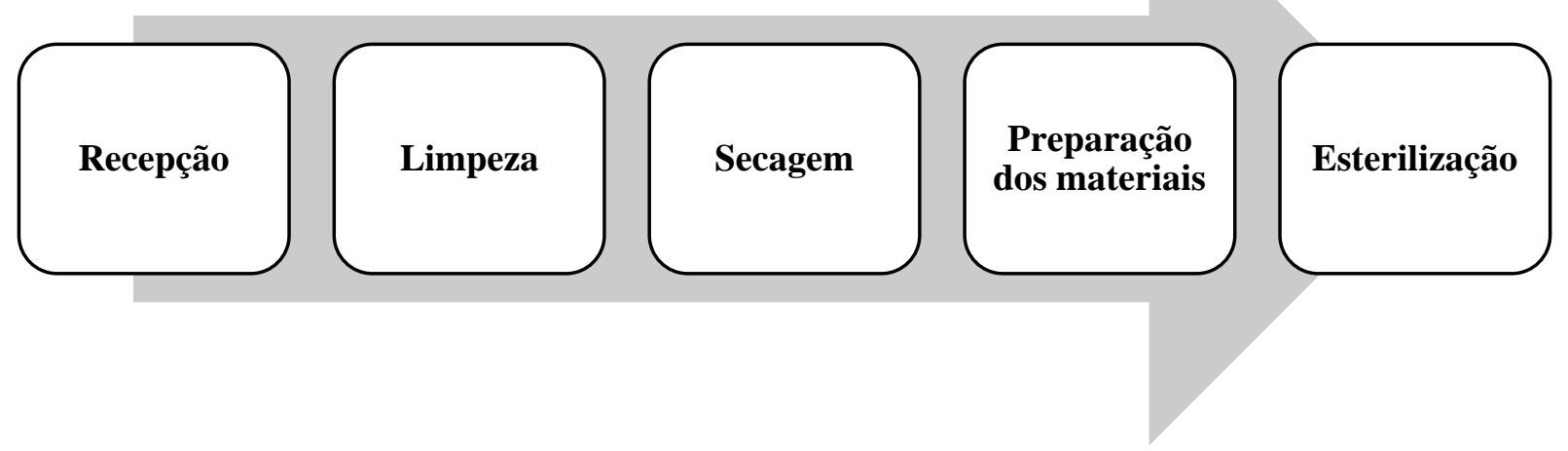

Figura 3 - Procedimento Operacional Padrão

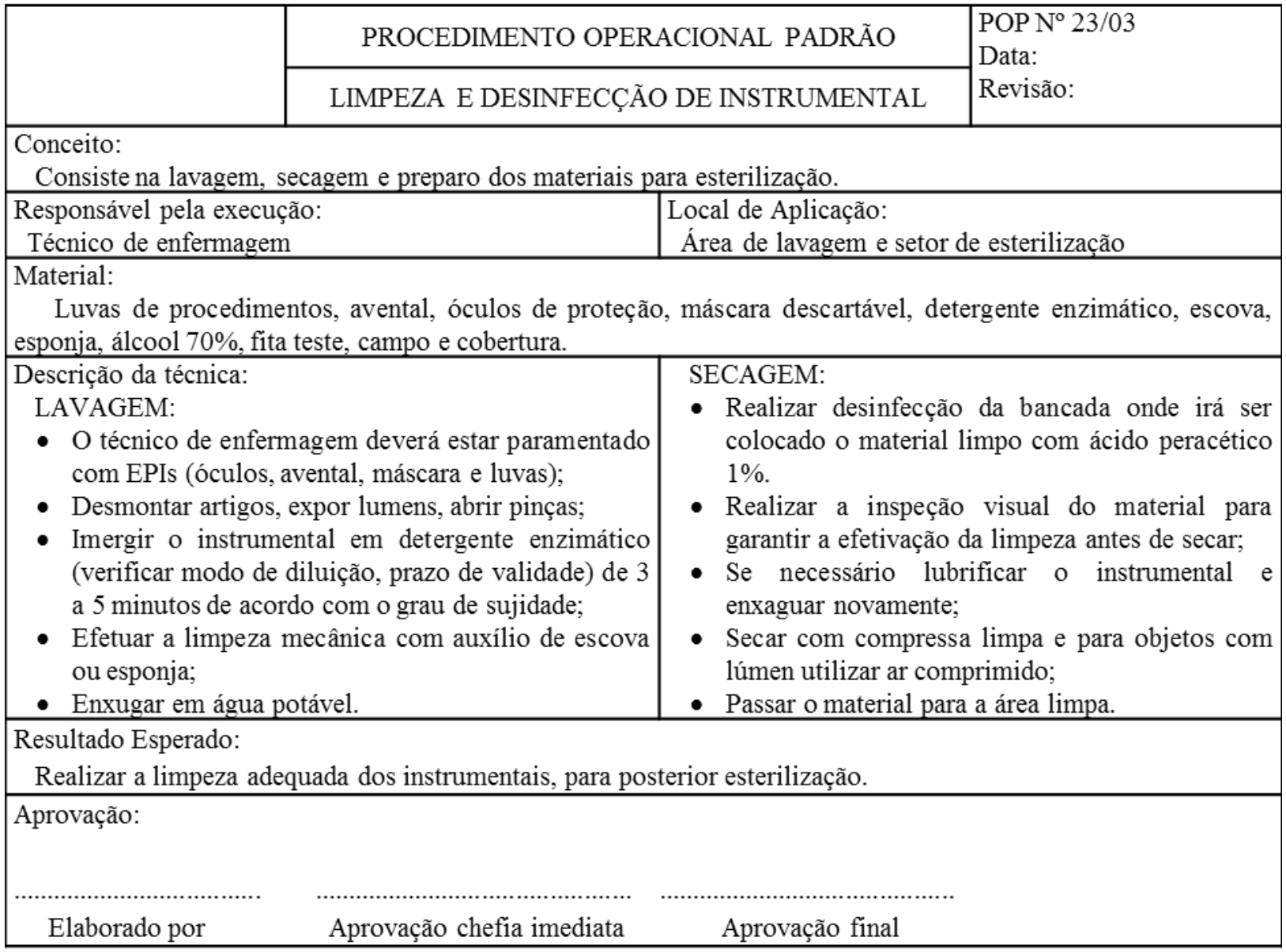

A partir dos dados das entrevistas e observações, foi possível construir o HTA. Primeiramente, definiu-se o objetivo do processo, o primeiro item na hierarquia. Após, foram determinadas as metas necessárias para atingir o objetivo principal, compondo o segundo nível hierárquico. As metas, por sua vez, foram decompostas em tarefas e/ou subtarefas, que devem ser realizadas para concretizar o objetivo final (Figura 4). Com as saídas do HTA, foi possível montar o Quadro 1, que esquematiza algumas das lacunas existentes observadas nos procedimentos padrão de limpeza atuais e exemplifica discrepâncias entre o prescrito pelo POP, o realizado pelo operador e a melhor situação proposta pelo HTA. 
Figura 4 - HTA do processo de preparação para esterilização

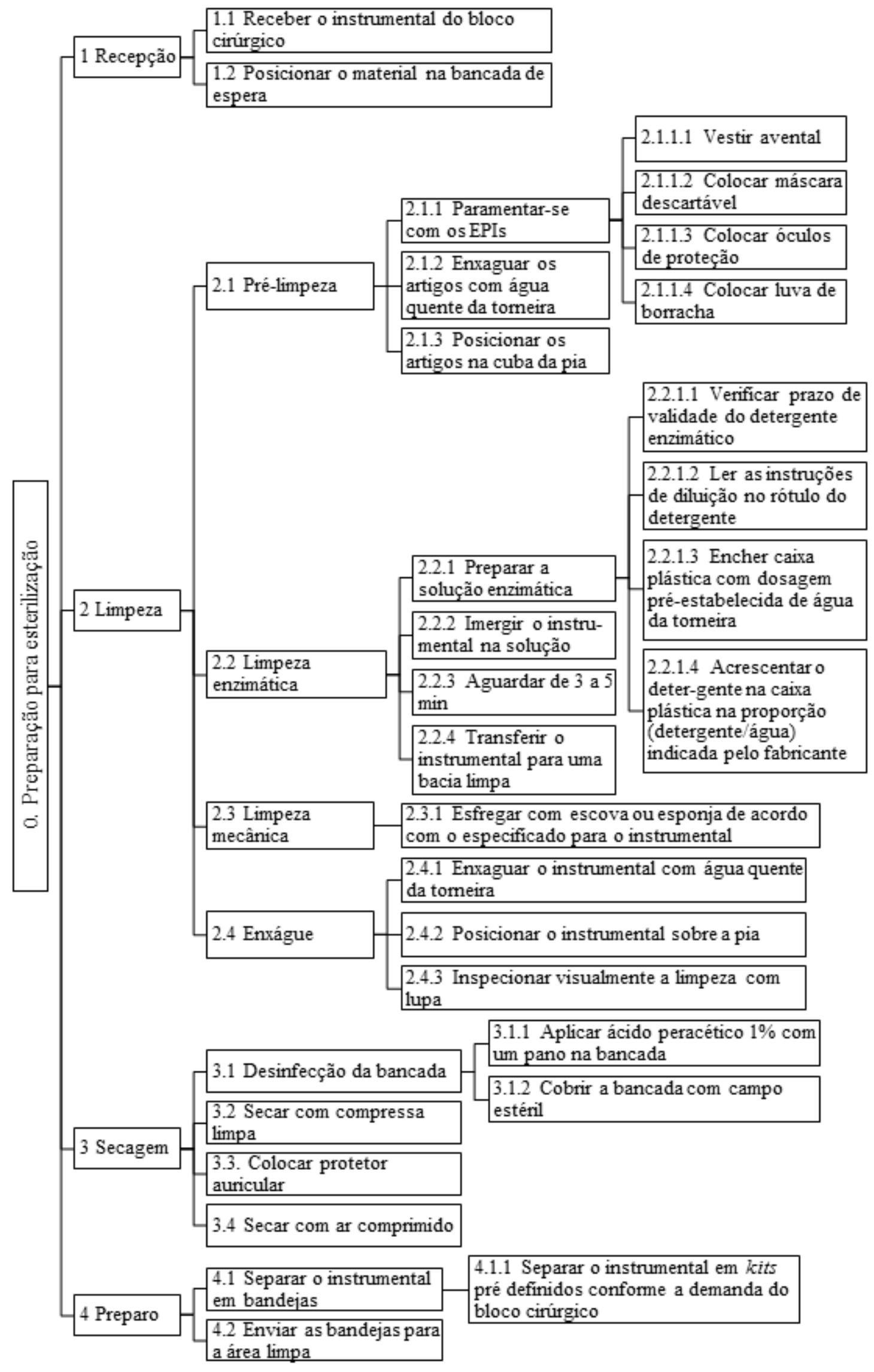


Quadro 1 - Lacunas e discrepâncias do processo prescrito e realizado

\begin{tabular}{|c|c|c|c|}
\hline $\begin{array}{l}\text { Tarefa ou } \\
\text { Subtarefa }\end{array}$ & Prescrito POP & Realizado Operador & Proposto HTA \\
\hline 2.1 .1 & $\begin{array}{l}\text { O técnico de enfermagem deverá } \\
\text { estar paramentado com EPIs } \\
\text { (óculos, avental, máscara e } \\
\text { luvas). }\end{array}$ & Usa luvas cirúrgicas. & $\begin{array}{l}\text { Vestir avental; } \\
\text { Colocar máscara descartável; } \\
\text { Colocar óculos de proteção; } \\
\text { Colocar luva de borracha. }\end{array}$ \\
\hline 2.1 .2 & Ausente & $\begin{array}{l}\text { Enxágua os artigos com } \\
\text { água quente. }\end{array}$ & $\begin{array}{l}\text { Enxaguar os artigos com água } \\
\text { quente. }\end{array}$ \\
\hline 2.2 .1 & Ausente & $\begin{array}{l}\text { Enche uma das cubas da } \\
\text { pia com água sem } \\
\text { dosagem prévia; } \\
\text { Acrescenta detergente a } \\
\text { mais do que o } \\
\text { recomendado pelo } \\
\text { fabricante. }\end{array}$ & $\begin{array}{l}\text { Verificar prazo de validade do } \\
\text { detergente enzimático; } \\
\text { Ler as instruções de diluição no } \\
\text { rótulo do detergente enzimático; } \\
\text { Encher caixa plástica com água da } \\
\text { torneira com dosagem pré- } \\
\text { estabelecida; } \\
\text { Acrescentar o detergente na caixa } \\
\text { plástica na proporção } \\
\text { (detergente/água) indicada pelo } \\
\text { fabricante. }\end{array}$ \\
\hline 2.4 & $\begin{array}{l}\text { Enxugar com água potável. } \\
{[\ldots]} \\
\text { Realizar a inspeção visual do } \\
\text { material para garantir a } \\
\text { efetivação da limpeza antes de } \\
\text { secar; }\end{array}$ & $\begin{array}{l}\text { Enxágua com água quente } \\
\text { da torneira. }\end{array}$ & $\begin{array}{l}\text { Enxaguar o instrumental com água } \\
\text { quente da torneira; } \\
\text { Posicionar o instrumental sobre a pia; } \\
\text { Inspecionar visualmente a limpeza } \\
\text { com lupa. }\end{array}$ \\
\hline
\end{tabular}

\subsection{Análise dos Erros e Proposição de Melhorias}

A partir dos resultados do HTA foi possível identificar os prováveis erros em cada tarefa e elencar medidas preventivas para coibi-los. Assim, foi realizada essa análise para os erros relacionados aos itens 2.1, 2.2, 2.3 e 2.4 do HTA. O Quadro 2 ilustra os procedimentos e resultados obtidos pela aplicação do HTA.

Com base na análise realizada, algumas melhorias podem ser sugeridas. Como por exemplo, na tarefa 2.1.1, o POP prescreve a paramentação do operador sem especificação adequada dos EPIs, tal como o tipo de luva. O adequado seria a utilização de luvas de borracha, sendo que o operador porta somente luvas cirúrgicas, sem os outros EPIs. Além disso, não consta na ordem das operações a indicação da sequência dos passos para vestir os equipamentos de proteção, indicando possibilidades de capacitação a posteriori. Isto, observado de acordo com a realização do HTA implicaria na ordenação dos procedimentos incluindo a hierarquização dos passos para portar adequadamente os EPIs. 
Quadro 2-Análise dos erros dos itens 2.1 a 2.4

\begin{tabular}{|c|c|c|c|}
\hline Tarefa/Subtarefa & Possibilidade de erro & Medida Reativa & Medida Preventiva \\
\hline 2.1.1.1 Vestir avental & Não vestir o avental & & Capacitação do operador \\
\hline 2.1.1.2 Colocar máscara descartável & $\begin{array}{l}\text { Não colocar máscara } \\
\text { descartável }\end{array}$ & & Capacitação do operador \\
\hline 2.1.1.3 Colocar óculos de proteção & $\begin{array}{l}\text { Não colocar óculos de } \\
\text { proteção }\end{array}$ & & Capacitação do operador \\
\hline 2.1.1.4 Colocar luva de borracha & $\begin{array}{l}\text { Não colocar luva de } \\
\text { borracha }\end{array}$ & & Capacitação do operador \\
\hline $\begin{array}{l}\text { 2.1.2 Enxaguar os artigos com água } \\
\text { quente da torneira }\end{array}$ & Não enxaguar & & Capacitação do operador \\
\hline $\begin{array}{l}\text { 2.1.3 Posicionar os artigos na cuba da } \\
\text { pia }\end{array}$ & Não posicionar & & Capacitação do operador \\
\hline \multirow{3}{*}{$\begin{array}{l}\text { 2.2.1.1 Verificar prazo de validade do } \\
\text { detergente enzimático }\end{array}$} & Não verificar o prazo & & Capacitação do operador \\
\hline & $\begin{array}{l}\text { Estar fora do prazo de } \\
\text { validade }\end{array}$ & $\begin{array}{l}\text { Abre novo } \\
\text { detergente } \\
\text { enzimático } \\
\end{array}$ & $\begin{array}{l}\text { Registro e controle } \\
\text { periódico do estoque de } \\
\text { materiais }\end{array}$ \\
\hline & $\begin{array}{l}\text { Ler errado o prazo de } \\
\text { validade }\end{array}$ & & $\begin{array}{l}\text { Etiquetar o prazo de } \\
\text { validade de maneira mais } \\
\text { visível no frasco do } \\
\text { produto }\end{array}$ \\
\hline \multirow[b]{2}{*}{$\begin{array}{l}\text { 2.2.1.2 Ler as instruções de diluição } \\
\text { no rótulo do detergente }\end{array}$} & Não ler as instruções & & Capacitação do operador \\
\hline & Ler errado as instruções & & $\begin{array}{l}\text { Transcrever as instruções } \\
\text { para fora do rótulo de } \\
\text { forma mais visível }\end{array}$ \\
\hline \multirow{2}{*}{$\begin{array}{l}\text { 2.2.1.3 Encher caixa plástica com } \\
\text { dosagem pré-estabelecida de água da } \\
\text { torneira }\end{array}$} & $\begin{array}{l}\text { Caixa plástica } \\
\text { indisponível }\end{array}$ & $\begin{array}{l}\text { Solicitação de } \\
\text { material ao } \\
\text { supervisor }\end{array}$ & $\begin{array}{l}\text { Registro e controle } \\
\text { periódico do estoque de } \\
\text { materiais }\end{array}$ \\
\hline & $\begin{array}{l}\text { Não medis o volume de } \\
\text { água adicionado }\end{array}$ & $\begin{array}{l}\text { Descartar água e } \\
\text { repetir } \\
\text { procedimento }\end{array}$ & $\begin{array}{l}\text { Uso de caixa plástica com } \\
\text { indicações de volume }\end{array}$ \\
\hline $\begin{array}{l}\text { 2.2.1.4 Acrescentar o detergente na } \\
\text { caixa plástica na proporção } \\
\text { (detergente/água) indicada pelo } \\
\text { fabricante }\end{array}$ & $\begin{array}{l}\text { Acrescentar quantidade } \\
\text { errada de detergente }\end{array}$ & $\begin{array}{l}\text { Descartar solução e } \\
\text { repetir } \\
\text { procedimento }\end{array}$ & $\begin{array}{l}\text { Uso de seringa para medir } \\
\text { a quantidade de detergente }\end{array}$ \\
\hline $\begin{array}{l}\text { 2.2.2 Imergir o instrumental na } \\
\text { solução }\end{array}$ & $\begin{array}{l}\text { Solução insuficiente para } \\
\text { imergir o instrumental } \\
\text { completamente }\end{array}$ & Imergir em etapas & $\begin{array}{l}\text { Verificar a quantidade de } \\
\text { instrumental antes de } \\
\text { preparar a solução }\end{array}$ \\
\hline 2.2.3 Aguardar de 3 a 5 min & $\begin{array}{l}\text { Aguardar menos/mais } \\
\text { tempo do que o indicado }\end{array}$ & Recomeçar 2.2 & $\begin{array}{l}\text { Setar alarme com o tempo } \\
\text { de espera necessário }\end{array}$ \\
\hline $\begin{array}{l}\text { 2.2.4 Transferir o instrumental para } \\
\text { uma bacia limpa }\end{array}$ & Bacia indisponível & $\begin{array}{l}\text { Solicitação de } \\
\text { material ao } \\
\text { supervisor. }\end{array}$ & $\begin{array}{l}\text { Registro e controle } \\
\text { periódico do estoque de } \\
\text { materiais }\end{array}$ \\
\hline $\begin{array}{l}\text { 2.3.1 Esfregar com escova ou esponja } \\
\text { de acordo com o especificado para o } \\
\text { instrumental }\end{array}$ & $\begin{array}{l}\text { Escova/esponja } \\
\text { indisponível }\end{array}$ & $\begin{array}{l}\text { Solicitação de } \\
\text { material ao } \\
\text { supervisor. }\end{array}$ & $\begin{array}{l}\text { Registro e controle } \\
\text { periódico do estoque de } \\
\text { materiais }\end{array}$ \\
\hline $\begin{array}{l}\text { 2.4.1 Enxaguar o instrumental com } \\
\text { água quente da torneira }\end{array}$ & $\begin{array}{l}\text { Deixar resíduo de } \\
\text { detergente no produto }\end{array}$ & $\begin{array}{l}\text { Enxaguar } \\
\text { novamente }\end{array}$ & $\begin{array}{l}\text { Conferir o enxágue antes } \\
\text { de passar para o próximo } \\
\text { passo }\end{array}$ \\
\hline $\begin{array}{l}\text { 2.4.2 Posicionar o instrumental sobre } \\
\text { a pia }\end{array}$ & Pia sem espaço & Liberar o espaço & $\begin{array}{l}\text { Verificar o espaço } \\
\text { disponível antes de iniciar } \\
\text { a limpeza. }\end{array}$ \\
\hline \multirow{3}{*}{$\begin{array}{l}\text { 2.4.3 Inspecionar visualmente a } \\
\text { limpeza com lupa }\end{array}$} & Lupa indisponível. & $\begin{array}{l}\text { Solicitação de } \\
\text { material ao } \\
\text { supervisor }\end{array}$ & $\begin{array}{l}\text { Registro e controle } \\
\text { periódico do estoque de } \\
\text { materiais. }\end{array}$ \\
\hline & $\begin{array}{l}\text { Falhar em realizar a } \\
\text { inspeção }\end{array}$ & $\begin{array}{l}\text { Realizar inspeção } \\
\text { na preparação }\end{array}$ & Capacitação do operador \\
\hline & Instrumental com sujidade & Recomeçar 2.3.1 & $\begin{array}{l}\text { Dar mais ênfase à } \\
\text { atividade } 2.3 .1\end{array}$ \\
\hline
\end{tabular}


Além deste exemplo, a tarefa 2.1.2, apresenta-se carente de instruções para sua realização no POP. Pelo HTA, foi possível identificar a sua existência e importância para atingir os resultados esperados do processo, uma vez que operador executa o procedimento de enxágue (pré-limpeza), pois verificou a sua necessidade empiricamente. A referida tarefa deveria ser acrescentada no POP, de maneira a garantir sua realização, independente do operador.

Ainda, uma tarefa de importância como a 2.2.1, que determina a preparação da solução enzimática, não é descrita no POP existente, sendo apenas informada, em ordem inadequada, a necessidade de verificar a validade e o modo de diluição. Também observa-se o total descumprimento por parte do operador das instruções de diluição da solução. O indicado seria a de reformulação do POP atual, incluindo o detalhamento da tarefa proporcionado pelo HTA, através da descrição passo-a-passo e em ordem cronológica correta da realização das tarefas do procedimento. Após a reformulação, o operador deveria ser capacitado para executar as novas etapas descritas.

Adicionalmente, tarefa 2.4 é apresentada com erro de grafia no POP (enxugar em vez de enxaguar) e de maneira pouco específica. A partir do HTA, foi possível perceber a colocação inadequada da observação sobre a inspeção visual após o enxágue na coluna de secagem do procedimento padrão atual. $\mathrm{O}$ operador, por sua vez, realiza apenas o enxágue do instrumental, sem realizar a inspeção visual indicada. Como melhoria, a tarefa deveria ser mais bem especificada, indicando a necessidade de utilizar água quente e realizar a validação do processo com lupa, tal como o obtido no HTA. A capacitação e conscientização do operador com relação a importância da inspeção correta também é indicada, para, assim, alcançar os resultados esperados.

\section{Conclusão}

O presente trabalho propôs executar uma metodologia que permitisse analisar processos hospitalares, de forma a identificar seus problemas e possíveis erros e sugerir melhorias que os previnam e/ou minimizem. O objetivo do estudo foi atingido, visto que a utilização do HTA possibilitou alcançar os resultados esperados no que diz respeito à eficácia na percepção dos problemas e no auxílio à visualização de soluções e medidas preventivas, exemplificados utilizando a etapa de limpeza do CME, que antecede a esterilização. Além, dos exemplos analisados neste artigo, é possível identificar a necessidade de redesenhar e dividir os POPs de todas as etapas que antecedem a esterilização, conforme as metas do HTA: recepção, limpeza, secagem e preparação. $\mathrm{Na}$ hierarquia, observou-se que cada meta possui tarefas e subtarefas específicas e demandam um procedimento próprio, que consiga atingir o nível de detalhamento necessário para orientar adequadamente o operador e garantir o sucesso e a segurança do processo. 
As principais limitações deste trabalho residiram nas restrições do tempo de aplicação da pesquisa, impedindo a observação e análise do processo completo de esterilização, bem como a implementação das mudanças sugeridas. Como possibilidade de trabalhos futuros, indica-se a expansão da metodologia de análise para todo os processos do CME e bloco cirúrgico. Ainda, sugere-se a implantação das melhorias propostas, bem como a medição e quantificação dos impactos diretos e indiretos destas mudanças para o processo, seus envolvidos e o setor como um todo.

\section{Abstract}

The health care processes and their related services dynamism and complexity imply process and human factors investments. For keeping competitive, the hospital - as productive organization - also needs to adapt to current market demands, seeking the organizational procedures improvement. This study analyzes the processes and human factors at a hospital's Centre of Materials and Sterilization, aiming its optimization, as well as error prediction during observed activities. To carry out the study, HTA method was used, which allows pointing and preventing errors and losses through the task process hierarchy. As a survey result, was obtained the procedure details, its process possible errors identification and their preventive measures.

Keywords: processes, tasks, HTA, processes improvements, hospitals

\section{Referências}

AGÊNCIA NACIONAL DE VIGILÂNCIA SANITÁRIA - ANVISA. Resolução RDC nº 15, de 15 de março de 2012. Dispõe sobre requisitos de boas práticas para o processamento de produtos para saúde e dá outras providências. ANVISA Publicações Eletrônicas, 2001.

ADAMS, P.; DAVID, G. C. Light vehicle fuelling errors in the UK: the nature of the problem, its consequences and prevention. Applied Ergonomics, v. 38, n. 5, p. 499-511, 2007. crossref

BATES, D.W. Using information technology to reduce rates of medication errors in hospitals. BMJ, v. 320, p. 788-791, 2000. crossref

BITTAR, O. J. Gestão de processos e certificação para qualidade em saúde. Revista da Associação Médica Brasileira, v. 45 , n. 4 , p. $357-363,1999$. crossref

BITTAR, O. J. Hospital: Qualidade e Produtividade. São Paulo: Sarvier, 1997.

BRATZ, M. Aplicação do QFD nas consultas eletivas do plantão médico da Santa Casa de Porto Alegre. 2001. 160 f. Dissertação (Mestrado Profissionalizante em Engenharia) - Universidade Federal do Rio Grande do Sul, Porto Alegre, 2001.

CARDOSO, V.; CAULliRAUX, H. M.; PAIM, R.; CLEMENTE, R. Gestão de Processos: pensar, agir e aprender. São Paulo: Bookman, 2009.

CARVALHO, M.; VIEIRA, A. A. Erro médico em pacientes hospitalizados. Jornal de Pediatria, v.78, n. 4, p. 261269, 2002. crossref 
CARVALHO, V. T.; CASSIANI, S. H. B. Erros na medicação: análise das situações relatadas pelos profissionais de enfermagem. Medicina, Ribeirão Preto, v. 33, p. 322-330, 2000.

CECÍlLIO, L. C. O.; MERHY, E. E. O singular processo de coordenação dos hospitais. Revista Saúde em Debate, v. 22, n. 64, p. 110-122, 2003.

DEJOURS, C.; DESSORS, D.; DESRIAUX, F. [trad. Maria Irene S. Betiol]. Por um trabalho, fator de equilíbrio. Revista de Administração de Empresas, v. 33, n. 3, p. 98-104, 1993. crossref

DUARTE, E. R. M. Avaliação e custeio de processos hospitalares: um estudo de caso no Hospital de Clínicas de Porto Alegre. 1995. 396 f. Dissertação (Mestrado em Administração) - Universidade Federal do Rio Grande do Sul, Porto Alegre, 1995.

GADD, K. Business self-assessment: a strategic tool for building process robustness and achieving integrated management. Business Process Reengineering \& Management Journal, v. 1, n. 3, p. 66-85, 1995. cross ref

GOMES, M. C. Organização e gestão do centro cirúrgico de um hospital universitário de Belo Horizonte - Minas Gerais. 2009. 122 f. Dissertação (Mestrado em Enfermagem) - Universidade Federal de Minas Gerais, Belo Horizonte, 2009.

HARRINGTON, H. J. Business Process Improvement. New York: McGraw Hill, 1991.

HODGKINSON, G. P.; CRAWSHAW, C. M. Hierarchical task analysis for ergonomics research: an application of the method tothe design and evaluation of sound mixing consoles Applied Ergonomics, v. 16, n. 4, p. $289-299$, 1985. crossref

InStITUTE OF MEDICINE. To Err Is Human: Building a Safer Health System. Washington: The National Academies Press, 2000.

JAMES, J. T. A new, evidence-based estimate of patient harms associated with hospital care. Journal Patient Safety, v. 9 , n. 3, p. 122-128, 2013. crossref

KIRWAN, B.; AINSWORTH, L. K. A Guide to Task Analysis. London: Taylor \& Francis, 1992. cross ref

KLOECKNER, A. P.; AMARAL, F. G.; ZIZEMER, V. A. S.; SANTOS, C. L. S. Integración del Análisis Ergonómico del Trabajo y del Análisis Jerárquico de la Tarea - Estudio de caso en una industria de pintura artística. Ingeniería Industrial. Actualidad y Nuevas Tendencias, v. 3, n. 11, p. 57-66, 2013.

LANE, R.; STANTON, N. A.; HARRISON, D. Applying hierarchical task analysis to medication administration errors. Applied Ergonomics, v. 37, 2007.

MATOS, E.; PIRES, D. Teorias administrativas e organização do trabalho: de Taylor aos dias atuais, influências no setor saúde e na enfermagem. Texto contexto enferm, v. 15, p. 508-514, 2006.

MILLS, S. Contextualising design: Aspects of using usability context analysis and hierarchical task analysis for software design. Behaviour \& Information Technology, v. 26, n. 6, p. 499-506, 2007. crossref

PASQUALI, R C. Metodologia para melhoria de processos de linha de frente em serviços: aplicação em laboratório de análises clínicas. 2002. 118 f. Dissertação (Mestrado em Engenharia de Produção) - Universidade Federal de Santa Catarina, Florianópolis, 2002.

PONTALTI, G. A sistematização da gestão baseada em atividades (ABM) - Activity-Based Management - para aplicação na área hospitalar - Caso Centro de Terapia Intensiva de um Hospital Universitário público. 2002.150 f. Dissertação (Mestrado Profissionalizante em Engenharia) - Universidade Federal do Rio Grande do Sul, Porto Alegre, 2002.

REASON, J. Combating omission errors through task analysis and good reminders. Quality and Safety in Healthcare, v. 11, n. 1 , p. $40-44,2002$. cross ref

REASON, J. Human error: models and management. BMJ 2000; 320:768-70. crossref 
ROSA, L.; Fatores intervenientes no trabalho coletivo dos profissionais de enfermagem: uma proposta de ação. 2010. 127 f. Dissertação (Mestrado em Engenharia de Produção) - Universidade Federal do Rio Grande do Sul, Porto Alegre, 2010.

ROSA M. T. L.; RODRIGUES, A. M.; CASTEllanOS, B. E. P.; AlMEIDA, M. C. P.; MENDES, S. A. A. O desenvolvimento técnico-científico da enfermagem - uma aproximação com instrumentos de trabalho. Anais $41^{\circ}$ Congresso Brasileiro de Enfermagem, Florianópolis, 1989.

SALMON, P.; JENKINS, D.; STANTON, N.; WALKER, G. Hierarchical task analysis vs. cognitive work analysis: comparison of theory, methodology and contribution to system design. Theoretical Issues in Ergonomics Science, v. 11, n. 6 , p. 504-531, 2010. crossref

SARKER, S. K.; CHANG, A.; ALBRANI, T.; VINCENT, C. Constructing hierarchical task analysis in surgery. Surgical Endoscopy, v. 22, n. 1, p. 107-111, 2008. crossref

SARKER, S. K.; HUTCHINSON, R.; CHANG, A.; VINCENT, C.; DARZI, W.W. Self-appraisal hierarchical task analysis o flaparoscopic surgery performed by expert surgeons. Surgical Endoscopy, v. 20, n. 4, p. 636-640, 2006. cross ref

SCHOLOSSMACHER, R.; Proposta de sistemática de avaliação de sobrecarga lombar causada por condições de trabalho: um estudo de caso em clínica geriátrica. Dissertação de Mestrado - Universidade Federal do Rio Grande do Sul, Porto Alegre, 2012.

SERRANHEIRA, F.; UVA, A.; SOUSA, P. Ergonomia hospitalar e segurança do doente: mais convergências que divergências. Rev Port Saúde Pública, v. 10, p. 58-73, 2010.

SOBECC. SOCIEDADE BRASILEIRA DE ENFERMEIROS DE CENTRO CIRÚRGICO, RECUPERAÇÃO ANESTÉSICA E CENTRO DE MATERIAL E ESTERILIZAÇÃO. Práticas Recomendadas da SOBECC: Centro Cirúrgico, Recuperação Anestésica e Centro de Material e Esterilização. São Paulo: SOBECC, 2000.

STANTON, N. A. Human Factor Methods: A Practical Guide for Engineering and Design. Ashgate Publishing Co., 2005.

STANTON, N. A. The handbook of human factors and ergonomics methods. CRC Press: 2005.

VLASTARAKOS, P. V.; NIKOLOPOULOS, T. P. The Interdisciplinary Model of Hospital Administration: Do Health Professionals and Managers Look at It in the Same Way. European Journal of Public Health, p. 1-6, 2007.

WERKEMA, M. C. C. As Ferramentas da Qualidade no Gerenciamento de Processos. Belo Horizonte: Fundação Christiano Ottoni, Escola de Engenharia, 1995.

YIN a, R. K. Estudo de Caso: Planejamento e métodos. $2^{\text {a }}$ Edição. Porto Alegre: Bookman, 2001.

\section{Dados dos autores:}

Nome completo: Vivian Pizzato Nunes

Filiação institucional: Universidade Federal do Rio Grande do Sul - UFRGS

Departamento: Engenharia de Produção e Transportes

Função ou cargo ocupado: Engenheira de Produção

Endereço completo para correspondência: Av. Osvaldo Aranha, $99-5^{\circ}$ andar, centro, Porto Alegre, RS, Brasil, CEP 90035-190

Telefones para contato: 555133084292

E-mail:vivipn@gmail.com 
Nome completo: Fernando Gonçalves Amaral

Filiação institucional: Universidade Federal do Rio Grande do Sul - UFRGS

Departamento: Programa de Pós-Graduação em Engenharia de Produção

Função ou cargo ocupado: Professor Associado

Endereço completo para correspondência: Av. Osvaldo Aranha, $99-5^{\circ}$ andar, centro, Porto Alegre, RS, Brasil, CEP 90035-190

Telefones para contato: 555133084292 - 555133083491

E-mail: amaral@producao.ufrgs.br

Submetido em: 06-11-2015

Aceito em: 15-06-2016 